\title{
Application of Silica-Coated Magnetite on a Steel Plate and its Frictional and Thermal Effect
}

\author{
Indri Dayana ${ }^{1}$, Anggito P. Tetuko ${ }^{2 *}$, Timbangen Sembiring ${ }^{1}$, Kurnia Sembiring ${ }^{1}$, Nining S. Asri², \\ Eko A. Setiadi², Juliaster Marbun', Martha Rianna', Masno Ginting², Perdamean Sebayang² \\ ${ }^{1}$ Department of Physics, Universitas Sumatera Utara, Jl. Bioteknologi No. 1, Padang Bulan, Medan 20155, Indonesia \\ 2 Research Center for Physics, Indonesian Institute of Sciences (LIPI), Bld. 440-442 Puspiptek Office Area, Tangerang Selatan, \\ 15314 Banten, Indonesia \\ *Corresponding author, e-mail: anggito.pringgo.tetuko@lipi.go.id
}

Received: 30 August 2020, Accepted: 04 November 2020, Published online: 02 December 2020

\begin{abstract}
The magnetite $\left(\mathrm{Fe}_{3} \mathrm{O}_{4}\right)$ particles that have been coated using tetraethyl orthosilicate (TEOS) as silica precursors were used as the additive in the lubricant. The effects of silica-coated magnetite additive on the thermal properties of ferro-lubricant and reducing the friction on a steel plate have been investigated. The characterizations were conducted at both conditions: with and without the addition of $\mathrm{Fe}_{3} \mathrm{O}_{4}$ particles. The characterization using TEM proposed that the average particle size of the silica-coated magnetite particles is $150 \mathrm{~nm}$. The TGA/DSC curves of the silica-coated magnetite particles suggested a gradual weight loss obtained as the temperature increased. The endothermic peak was obtained at $\sim 37$ and $50^{\circ} \mathrm{C}$. The silica-coated magnetite particles' additive increases both the density and viscosity of $0.84 \mathrm{~g} / \mathrm{cm}^{3}$ and $134.29 \mathrm{cSt}$. The silica-coated magnetite particles additive in the lubricant enhances the thermal conductivity and specific heat of $0.151 \mathrm{~W} / \mathrm{m} . \mathrm{K}$ and $1600 \mathrm{~J} / \mathrm{kg}$.K. Ferro-lubricant reduces the friction coefficient up to 0.02 (static) and 0.005 (dynamic). The wear resistance of the plate could be improved as analyzed using an optical microscope. These results demonstrate a promising application of the silica-coated magnetite particles as an additive in the lubricant. Therefore improving wear resistance and cooling during the friction process.
\end{abstract}

Keywords

magnetite particles, silica-coated, ferro-lubricant, friction, thermal properties

\section{Introduction}

In the engine, the friction between two moving parts (e.g., gears and piston) could not be eliminated as part of their primary function and only can be reduced to a certain level [1-4]. The friction could also cause heat and damage to the components. Thus, the manufacturer or industry has to spend high maintenance costs to replace the components that contribute to the overall energy losses [1-4]. An effective lubrication system plays an essential role in mechanical equipment due to the high mechanical failure caused by friction and wears $[5,6]$. Lubrication is widely employed to improve the efficiency of energy utilization and mechanical durability [7-10]. Lubricants are mainly composed of mineral-based oils containing saturated hydrocarbon polymers and compounds (e.g., sulfur and phosphorus). The friction occurred on the moving parts of the machine component can be reduced using lubricants. It could create additional layers between the parts.
Lubricants could also act as a coolant to remove the heat due to the friction on the moving parts. The development of a new type of lubricant is required to improve the performance of the lubricants. It is also utilized to reduce friction and enhance the wear resistance of the material used as machine components and act as a cooling media. One of the current breakthroughs and proposed by many researchers is using the additive of material particles with nanometer size. Nanoparticles of materials have the characteristics of small size, large specific surface area, and durable surface activity that can significantly improve the lubrication performance. The utilization of material additives in nanoparticle size in lubricant presents many advantages. The additives are relatively insensitive to temperature, and tribo-chemical reactions are limited [11]. Another advantage of material additives is the ability to change its solubility under the effect of surface modification [12]. 
Many studies reported that lubricants that used additive effectively decrease the wear and friction caused by high pressures and temperatures [13-17]. However, the reduction depends on various factors, including the compatibility with the base lubricant. Other factors are particle size, morphologies, and the volume fraction between the particles additive and the base lubricant.

$\mathrm{Qu}$ et al. [18] analyzed polytetrafluoroethylene (PTFE) particles that have been filled with $\mathrm{SiO}_{2}$ nanoparticles and dispersed in the lubricant. The authors suggested that the friction coefficient is reduced at $0.6 \%$ additive concentration from 0.1 to 0.8 . On the other hand, the wear scar diameter decreased from 0.65 to $0.55 \mathrm{~mm}$ at similar particles' concentration. Wu et al. [19] investigated the friction coefficient and wear scar diameter in the lubricant that used $4 \%$ of $\mathrm{TiO}_{2}$ nano-additive. The authors found that the friction coefficient and the wear scar diameter can be minimized from 0.5 to 0.2 and 1000 to $750 \mu \mathrm{m}$ by using the $\mathrm{TiO}_{2}$ nanoparticles as the lubricant additive. Current studies in 2020 by Ren et al. [20] evaluated three different types of $\mathrm{ZnO} @$ graphene core-shell nanocomposite additives: prism, sheet, and rod. Based on their analysis, the $\mathrm{ZnO}$ additive could lower the friction coefficient from 0.12 (base oil without additive) to 0.05 (sheet-like $\mathrm{ZnO}$ ). The wear scar diameter could be decreased from 1 to $0.6 \mathrm{~mm}$ at $0.5 \%$ additive concentration. Another recent investigation by Wang et al. [21] suggested using $\mathrm{Ag} / \mathrm{Graphene}$ nanocomposite as a lubricant's additive. The authors used four additive percentages: $0.05,0.1,0.15$, and $0.2 \mathrm{wt} \%$. The friction coefficient and the wear surface diameter can be minimized from 0.11 to 0.08 (0.05 wt\%), and from 0.76 to $0.545 \mathrm{~mm}$, respectively.

Magnetite $\left(\mathrm{Fe}_{3} \mathrm{O}_{4}\right)$ particles can be used in different applications $[22,23]$; however, the use of magnetite $\left(\mathrm{Fe}_{3} \mathrm{O}_{4}\right)$ particles as the additive in the lubricant is limited. Only several researchers that focused on magnetite, such as conducted by Zhou et al. [24], Xiang et al. [25] and Xu et al. [26]. Zhou et al. [24] examined the friction coefficient and wear on carbon steel that has been lubricated using lubricant and $\mathrm{Fe}_{3} \mathrm{O}_{4}$ particles $(10 \mathrm{~nm})$ as the additive. Oleic acid was used to modify the surface of the particle to be easily dispersed in the lubricant. The friction coefficient could be reduced from 0.2 to 0.15 by adding $2 \mathrm{~g}$ of $\mathrm{Fe}_{3} \mathrm{O}_{4}$ into the 11 of lubricant. On the other hand, wear-loss-volume decreased to $64.7 \%$. Another researcher that used $\mathrm{Fe}_{3} \mathrm{O}_{4}$ particles as the additive in the lubricant is Xiang et al. [25], where nanoflakes $(\sim 80-100 \mathrm{~nm})$ were utilized. Their results suggested that by using $1.5 \%$ of $\mathrm{Fe}_{3} \mathrm{O}_{4}$ nanoflakes, the friction coefficient can be decreased from 0.095 to 0.075 , and the wear scar diameter can be reduced from 0.9 to $0.8 \mathrm{~mm}$. Xu et al. [26] also investigated the use of $\mathrm{Fe}_{3} \mathrm{O}_{4}$ spheres $(\sim 400-500 \mathrm{~nm})$ as the additive in the lubricant. $\mathrm{MoS}_{2}$ was used as a coating material to improve the particles' wettability in the lubricant. Based on their investigation, by adding $1 \mathrm{wt} \%$ of $\mathrm{Fe}_{3} \mathrm{O}_{4}$, the friction coefficient can be reduced from 0.16 to 0.10 .

Summarizing the research that used particles additive in the lubricant, the authors found several problems that need improvements. The problems are the stability of the particles in the lubricant and modification of the lubricant properties. The magnetite particles' surface needs a modification to enhance the dispersion stability of the ferro-lubricant. It also could be used to improve the thermal properties related to friction and wear reduction and its cooling capability.

One of the novelties proposed in this research is the use of tetraethyl orthosilicate (TEOS) with a low concentration of $1.2 \mathrm{ml}$ as silica precursors. TEOS was used to coat and modify the surface of the magnetite $\left(\mathrm{Fe}_{3} \mathrm{O}_{4}\right)$ particles into oleophilic. The silica-coated magnetite was then used as the additive in the lubricant without a sonication process. On the other hand, previous investigators have used oleic acid or sodium molybdate, and polyvinylpyrrolidone as the media for modifying the magnetite particles surface, and a sonication process was used in the lubricant synthesis. The thermal properties (e.g., thermal conductivity and specific heat) of the ferro-lubricant that used magnetite $\left(\mathrm{Fe}_{3} \mathrm{O}_{4}\right)$ particles as the additive also have never been investigated by previous researcher. These thermal properties measurement of ferro-lubricant is the second novelty proposed in this research. The synthesis process of ferro-lubricant that used magnetite particles as the additive is simple, low cost, and could be conducted quickly, and only a small additive is used.

\section{Materials and methods}

The solution that contains $60 \mathrm{ml}$ of distilled water, $240 \mathrm{ml}$ of ethanol, and $7.5 \mathrm{ml}$ of ammonia (18\%) were mixed. Then, tetraethyl orthosilicate (TEOS) as silica precursors $(1.2 \mathrm{ml})$ was added into the solution, followed by an additional $0.3 \mathrm{~g}$ of magnetite $\left(\mathrm{Fe}_{3} \mathrm{O}_{4}\right)$ particles to obtain the silica-coated particles. The solution was stirred using a magnetic stirrer for 6 hours at $45^{\circ} \mathrm{C}$ to produce a homogeneous solution. The precipitate was collected from the solution, separated using a permanent magnet bar, and washed several times by distilled water. The precipitate was dried in the oven overnight at $60{ }^{\circ} \mathrm{C}$, and the material was ground by using hand mortar to obtain 
the magnetite powders. Furthermore, $0.1 \mathrm{~g}$ of magnetite particles that have been coated using silica (TEOS) was added into $100 \mathrm{ml}$ of lubricant as the additive (volume fraction of $0.02 \%$ ). The ferro-lubricant was further analyzed using several measurements and characterizations. Transmission Electron Microscopy (TEM, Tecnai G2 S20 twin) was used to analyze the magnetite particle size and distribution. The magnetite particles' thermal behaviour at two different conditions: with and without silica (TEOS) coating, were characterized using Thermogravimetric analysis/Differential Scanning Calorimetry (TGA/DSC, Linseis, STA PT 1600). The densities of ferro-lubricant were measured using Pycnometer, and the viscosity analyses were performed based on ASTM D 3524 and D 445. On the other hand, the thermal conductivity and specific heat of the ferro-lubricant were measured using C-Therm, TCi thermal conductivity analyzer. The friction coefficients of ferro-lubricant with and without silica (TEOS) coating were examined using ATS-MAN-1008-IT-VAR at a pull speed of $150 \mathrm{~mm} /$ minute (ASTM D 1894). The plates' images after the friction test were analyzed using Keyence MD 2800 X digital optical microscope to investigate the wear caused by the friction.

\section{Results and discussions}

TEM images and particles size distribution of both uncoated and silica-coated magnetite $\left(\mathrm{Fe}_{3} \mathrm{O}_{4}\right)$ particles are presented in Fig. 1. The results suggested that the particles coated using silica (TEOS) have a larger average diameter
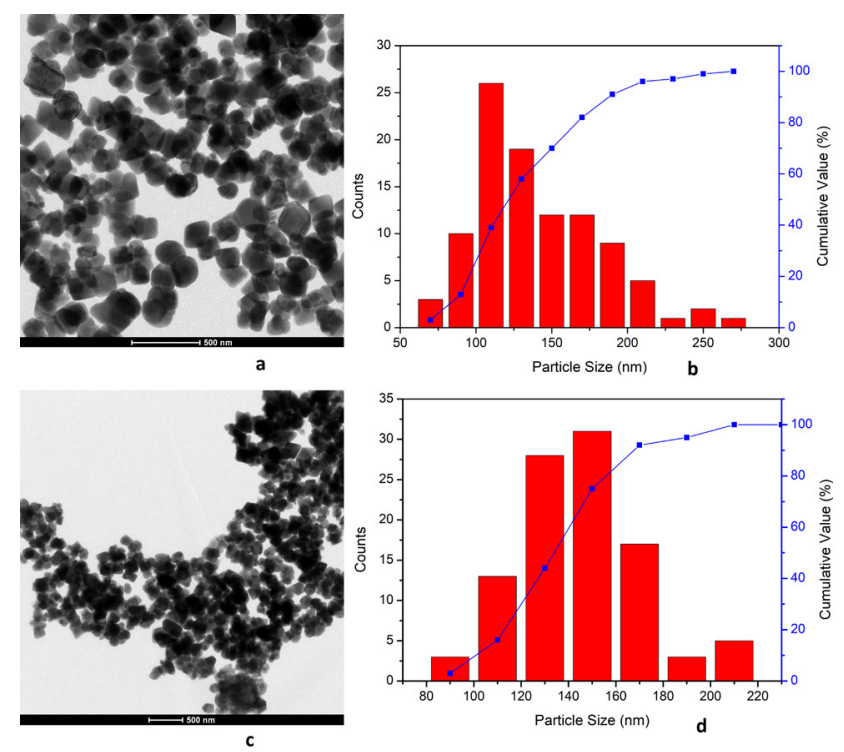

Fig. 1. a) TEM image of uncoated magnetite particles; b) Histogram of uncoated magnetite particles size; c) TEM image of silica-coated magnetite particles; d) Histogram of silica-coated magnetite particles size. of $150 \mathrm{~nm}$ than the uncoated particles with an average size of $120 \mathrm{~nm}$. Thus, silica layers have been successfully coated on the surface of the magnetite particles. The coating layer of silica, which has an oleophilic characteristic, is essential for the particles to be easily dispersed in the lubricant and improve stability [27-29]. The silica layer can also reduce the agglomeration and clustering of particles due to Van der Waals and magnetic forces between particles that affect the sedimentation of the particles and viscosity of ferro-lubricant $[30,31]$.

Fig. 2 presents the TGA and DSC curves of the uncoated magnetite $\left(\mathrm{Fe}_{3} \mathrm{O}_{4}\right)$ and the magnetite particles that have been coated using silica (TEOS) at a temperature range from room temperature to $65{ }^{\circ} \mathrm{C}$. In general, both magnetite samples (uncoated and silica-coated) lead to similar behavior. The material demonstrated a gradual slightly weight loss due to the evaporation of physisorbed water or the surface hydroxyl group's degradation at relatively low temperatures [31-33]. This result corresponds to previous research; a temperature range of $30-150{ }^{\circ} \mathrm{C}$ is the characteristic of loss of residual water and other contaminations [34]. However, the magnetite particles
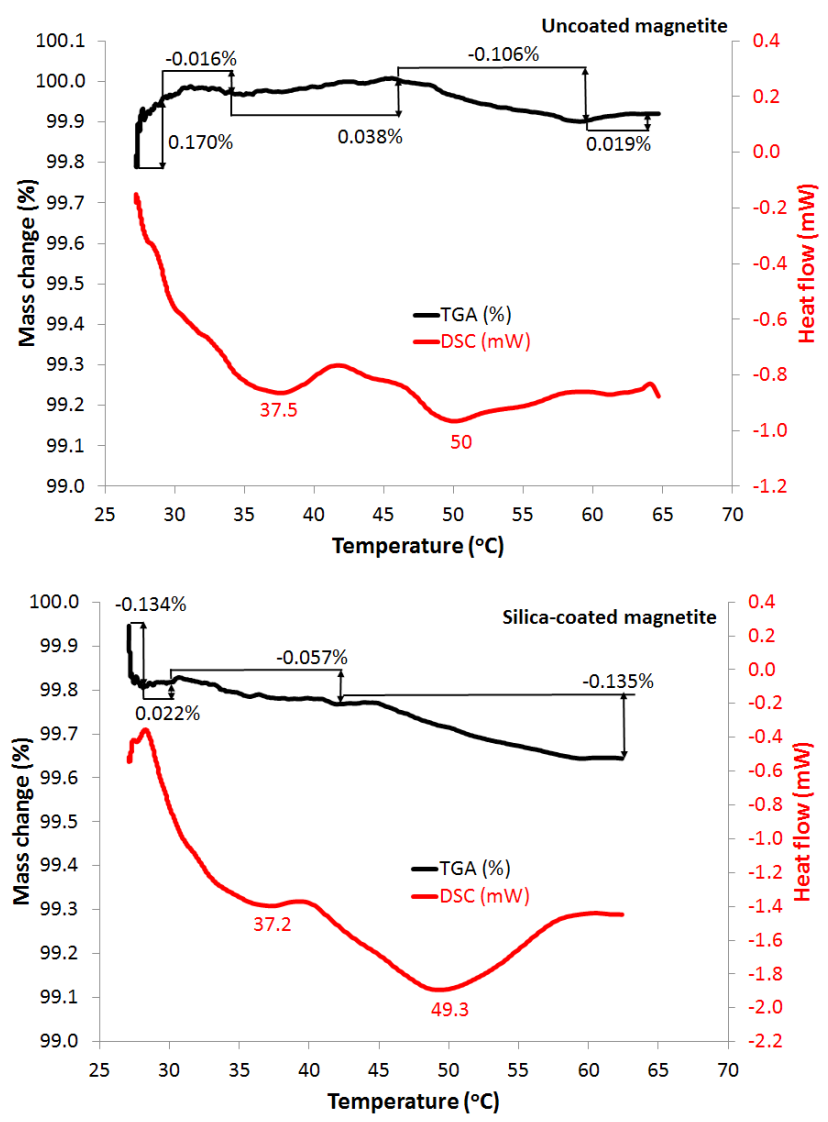

Fig. 2 TGA/DSC curves; a) Uncoated magnetite particles; b) Silica-coated magnetite particles. 
with silica-coated indicate higher mass changes $(-0.135 \%$ at $65{ }^{\circ} \mathrm{C}$ ) than the uncoated magnetite particles. This higher mass occurs due to the decomposition of the surfactant (TEOS) on the magnetite surface when the temperature increases [35]. Correspondingly, the DSC curves show two endothermic peaks at $\sim 37$ and $50{ }^{\circ} \mathrm{C}$, indicating that the maximum heat was absorbed into the sample. The endothermic peaks are related to the phase transition, reduction, and most decomposition reactions. In the curves, endothermic peaks correspond to weight loss from -0.016 and $-0.106 \%$ for the uncoated magnetite particles to -0.057 and $-0.135 \%$ for the silica-coated magnetite particles. This result has a good agreement with the previous research conducted by Lesiak et al. [34]. According to TGA/DSC results, the samples could be heated at a temperature of $60{ }^{\circ} \mathrm{C}$ to evaporate the water excess and not need further temperature treatment to avoid magnetite transformation into another phase.

The synthesized ferro-lubricant and the density of ferro-lubricant as a function of particle addition variation are shown in Fig. 3. The density of $0.84 \mathrm{~g} / \mathrm{cm}^{3}$ is obtained at 0.3 $\mathrm{g}$ of magnetite particles that have been coated using $1.2 \mathrm{ml}$ of TEOS that acts as the silica precursors. Then the particles $(0.1 \mathrm{~g})$ were immersed in $100 \mathrm{ml}$ of lubricant. The TEOS and particles addition in the lubricant was chosen because showing better liquid stability as analyzed in our previous investigation [36]. Based on the graph, the increase of the silica-coated magnetite particles ( 0.1 to $0.4 \mathrm{~g})$ used as the additive could enhance the density of ferro-lubricant from 0.84 to $0.88 \mathrm{~g} / \mathrm{cm}^{3}$. A similar trend was also observed by Syam Sundar et al. [37] when the volume concentration was increased in the magnetite-water nanofluid.

Viscosity is another critical factor of thermophysical properties, representing the internal resistance of fluid flow [38], and viscosity correlates with temperature [39]. Ferro-lubricant's viscosity analysis and its comparison

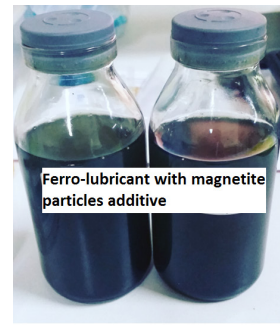

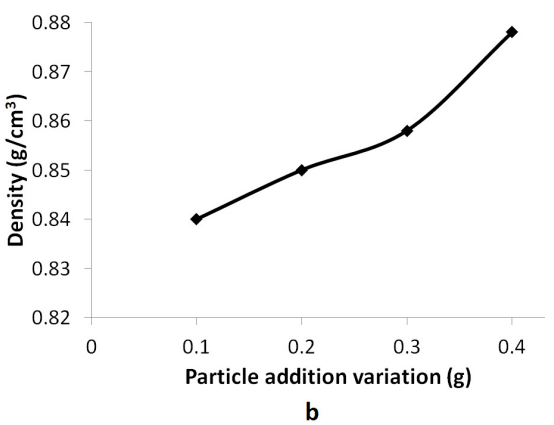

Fig. 3 a) Ferro-lubricant that have been synthesized in the laboratory; b) Density of ferro-lubricant as a function of particles addition variation. to the commercial lubricant at $40{ }^{\circ} \mathrm{C}$ are shown in Fig. 4 . The addition of silica-coated magnetite $\left(\mathrm{Fe}_{3} \mathrm{O}_{4}\right)$ particles in the lubricant increases the viscosity. The addition of magnetite particles affects the intermolecular forces and increases the contact between the base fluid and particles. Therefore increases the fluid resistance, which correlated to the improvement in viscosity. Another reason may be due to the increase in the molecular forces between particles (Newtonian behavior), enhancing the formation of particles clustered. Consequently, the resistance against particle motion is created between the fluid layers [40]. A similar trend was also observed by Asadi et al. 2016 [41], where viscosity improvement of up to $125 \mathrm{cSt}$ was obtained by adding $0.25 \%$ of MWCNT/ $\mathrm{MgO}$ particles that has been measured at $40{ }^{\circ} \mathrm{C}$. On the other hand, Chen et al. [42] proposed that by adding magnetite particles into the silicon oil, the viscosity enhanced up to $55 \mathrm{cSt}$ at the temperature measurement of $40^{\circ} \mathrm{C}$.

The thermal conductivity of both commercial lubricant and ferro-lubricant used silica-coated magnetite particles as the additive are shown in Fig. 5. Based on the graph, it can be concluded that the ferro-lubricant shows a higher thermal conductivity value compared to the commercial lubricant. This result proposed that the silica-coated magnetite particles additive in the lubricant could improve the overall thermal conductivity that could affect its cooling capability. Random movements caused by the Brownian motion of the silica-coated magnetite particles in the ferro-lubricant as the base fluid create a micro-convection and enhance its thermal conductivity [43]. An extended conductive path for the heat as a result of particles clustering in

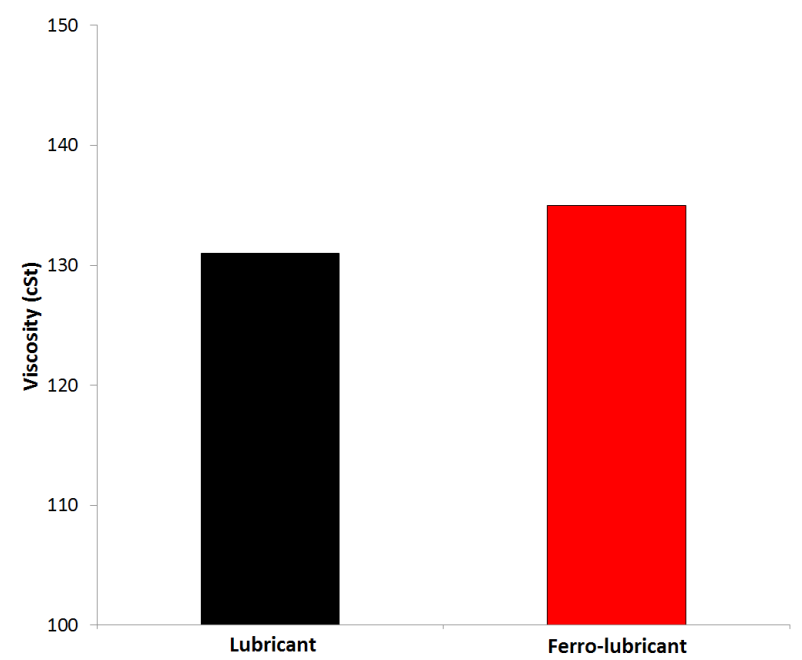

Fig. 4 Comparison of viscosity of ferro-lubricant and commercial lubricant. 


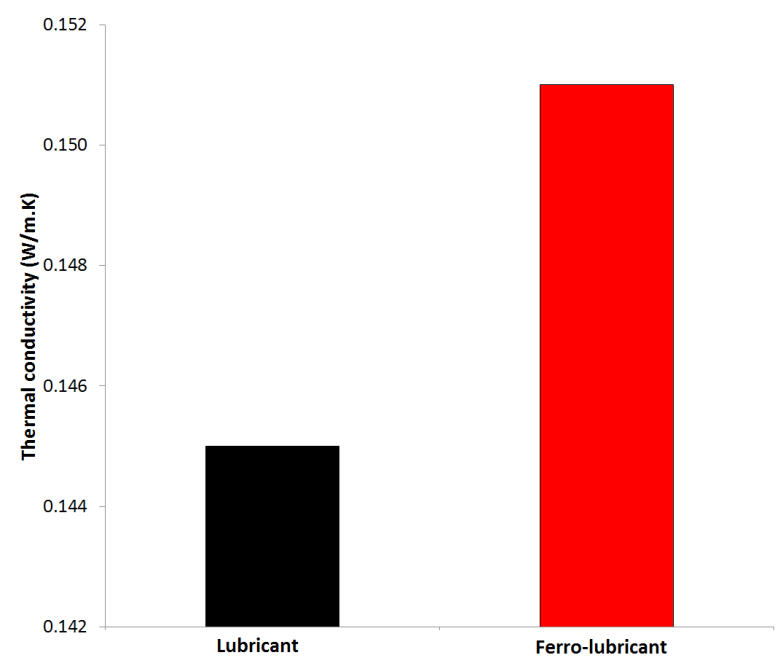

Fig. 5 Comparison of thermal conductivity of ferro-lubricant and commercial lubricant.

the ferro-lubricant could also improve the thermal conductivity value $[43,44]$. A comparison of thermal conductivity enhancement (from 0.135 to $0.138 \mathrm{~W} / \mathrm{m} . \mathrm{K}$ ) at a volume fraction of $0.02 \%$ was also proposed by Dinesh et al. [45], $\mathrm{ZnO}$ was used as the additive in engine oil. Another result from Yang et al. 2019 [46] also confirmed that the addition of $\mathrm{ZnO}$ nanoparticle additive in engine oil at a volume fraction of $0.25 \%$ could improve the thermal conductivity. The values were 0.139 to $0.140 \mathrm{~W} / \mathrm{m}$.K that have been measured at ambient temperature. This current investigation suggested that ferro-lubricant that used silica-coated magnetite $\left(\mathrm{Fe}_{3} \mathrm{O}_{4}\right)$ particles additive has better thermal conductivity value. The measurements were conducted at ambient temperature and at a volume fraction of $0.02 \%$. The finding from this current and previous experimental investigations confirmed the benefit of the particles additive. The additive could be used as a medium to increase the wear resistance and reduce the friction coefficient. Lubricant with particles additive, particularly magnetite, could also be used as a coolant to reduce the heat between the moving parts and engine.

Another thermal property that is an essential factor in the ferro-lubricant to absorb the heat on the moving parts is specific heat. This property ensures that the ferro-lubricant could store and carry the heat due to the moving parts' friction. Thus, besides being used to reduce friction and enhancing wear resistance, the ferro-lubricant also acts as the coolant for removing the heat efficiently on the moving parts. The comparison of specific heat in both commercial and ferro-lubricant are shown in Fig. 6. Based on the

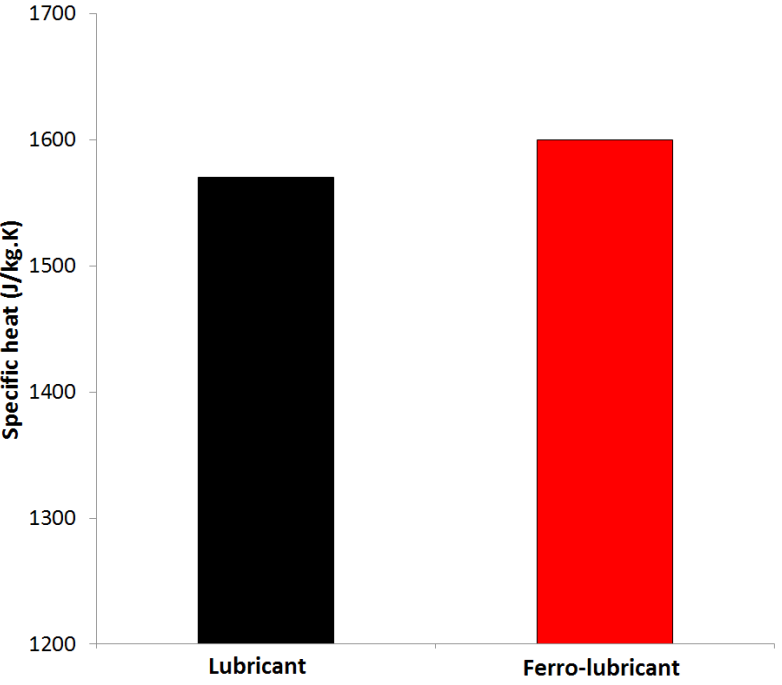

Fig. 6 Comparison of specific heat of ferro-lubricant and commercial lubricant.

graph, the addition of silica-coated magnetite particles in the lubricant improved the specific heat of the ferro-lubricant. The value enhances from 1586 to $1600 \mathrm{~J} / \mathrm{kg}$.K at a volume fraction of $0.02 \%$ measured at ambient temperature. The previous result investigated by Lin et al. 2018 [47], where $\mathrm{Al}_{2} \mathrm{O}_{3}$ with a volume fraction of $6 \%$, could enhance the specific heat up to $1800 \mathrm{~J} / \mathrm{kg}$.K. The author utilizes the nanofluid to be used as the chiller lubricant. Another study by Wrenick et al. 2005 [48] suggested that the specific heat of $2050 \mathrm{~J} / \mathrm{kg} . \mathrm{K}$ in the engine oil without particle additive was obtained (measured at ambient temperature).

The friction coefficient at two different steel plates lubricated using the commercial lubricant and the ferro-lubricant in both dynamic and static are shown in Fig. 7. The results show that the ferro-lubricant used silica-coated magnetite particle as the additive on the plate reduces the friction in both static and dynamic conditions. Previous research conducted by $\mathrm{Wu}$ et al. suggested a similar behavior where the additive of particles in lubricant could reduce the friction coefficient [49]. However, the friction and wear resistance on a surface that used ferro-lubricant as the lubrication media depend on the particle size and concentration (volume fraction) used as its additive $[50,51]$. The particles additive in the ferro-lubricant could modify the sliding friction in higher contact pressure on the moving parts into rolling friction that is usually is found in lower contact pressure. The friction characteristic change affects the wear resistance and friction coefficient due to tribo-film and interfacial interaction [52-54]. The silica-coated magnetite particles used as 


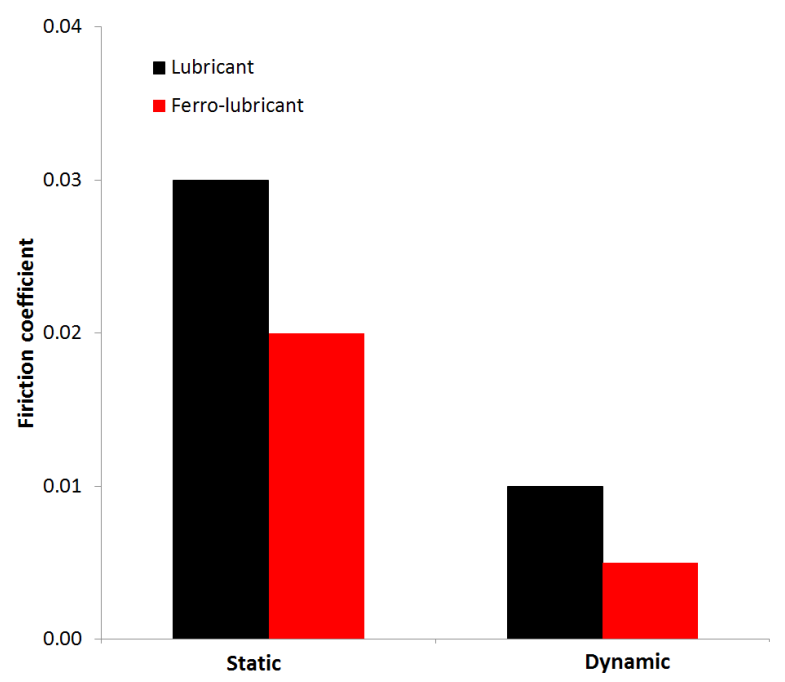

Fig. 7 Comparison of friction coefficient of ferro-lubricant and commercial lubricant.

the additive in the ferro-lubricant with magnetic behavior could also reduce the direct contact between the moving parts that decrease the friction $[26,55]$.

Figs. 8, 9, and 10 presented the comparison of two steel plates that have been analyzed using an optical microscope at two different lubrications: commercial and ferro-lubricant. The images confirmed that the silica-coated magnetite particles as lubricant additive increase the wear resistance and reduce wear on the plate sample due to the friction. The nanoparticles additive (smaller than the surface roughness) could fill the scars and groves and easily penetrate the contact interface. The additive could improve the separation and reduce its surface roughness with a tribo-film layer that could occur $[52,53]$. Another advantage of particles' utilization in the lubricant is the particles could reduce the moving parts'pressure. It could decrease the adhesion force and increase the separation that affects the overall friction coefficient [56].

\section{Conclusions}

The effects of silica-coated magnetite $\left(\mathrm{Fe}_{3} \mathrm{O}_{4}\right)$ particles as an additive in lubricant for improving the thermal properties of lubricant and its effect on reducing the friction on a steel plate have been investigated. The TEM image confirmed that the magnetite particles had been successfully coated using silica (TEOS) to increase its wettability and stability in the ferro-lubricant. TGA/DSC curves of both magnetite particles (with and without the silica coating) suggested a weight loss. The endothermic peak was obtained as the temperature increased. The results confirmed that the silica-coated magnetite particles' additive increases the density, viscosity, thermal conductivity, and specific heat of ferro-lubricant. Ferro-lubricant could reduce the friction coefficient and improve the wear resistance of a steel plate that has been lubricated compared to the commercial lubricant. The additive of silica-coated magnetite particles in lubricant has potential applications in industrial and automotive applications in both tribology and cooling aspects.

\section{Acknowledgments}

The authors would like to thank the Research Center for Physics Indonesian Institute of Sciences (LIPI) for the facilities used in this research and the support from Universitas Sumatera Utara (USU), Medan, Indonesia.

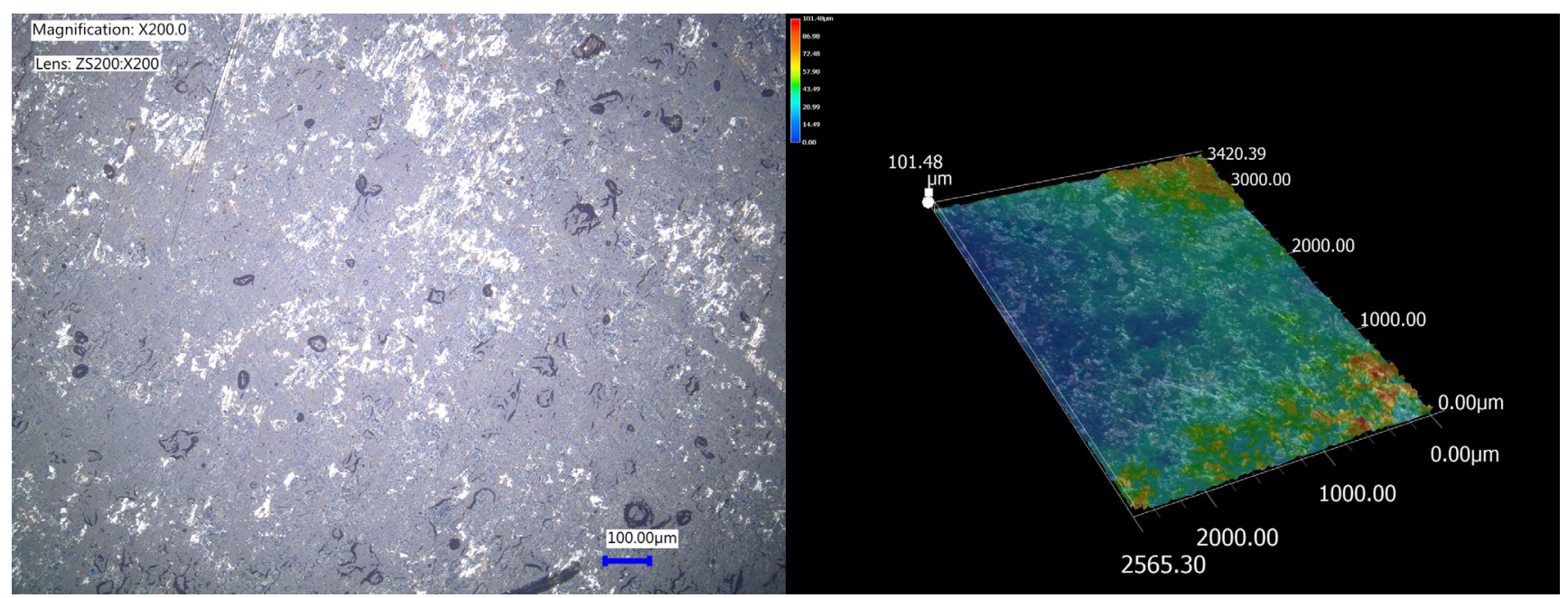

Fig. 8 Optical image on the surface of the steel plate (before test). 


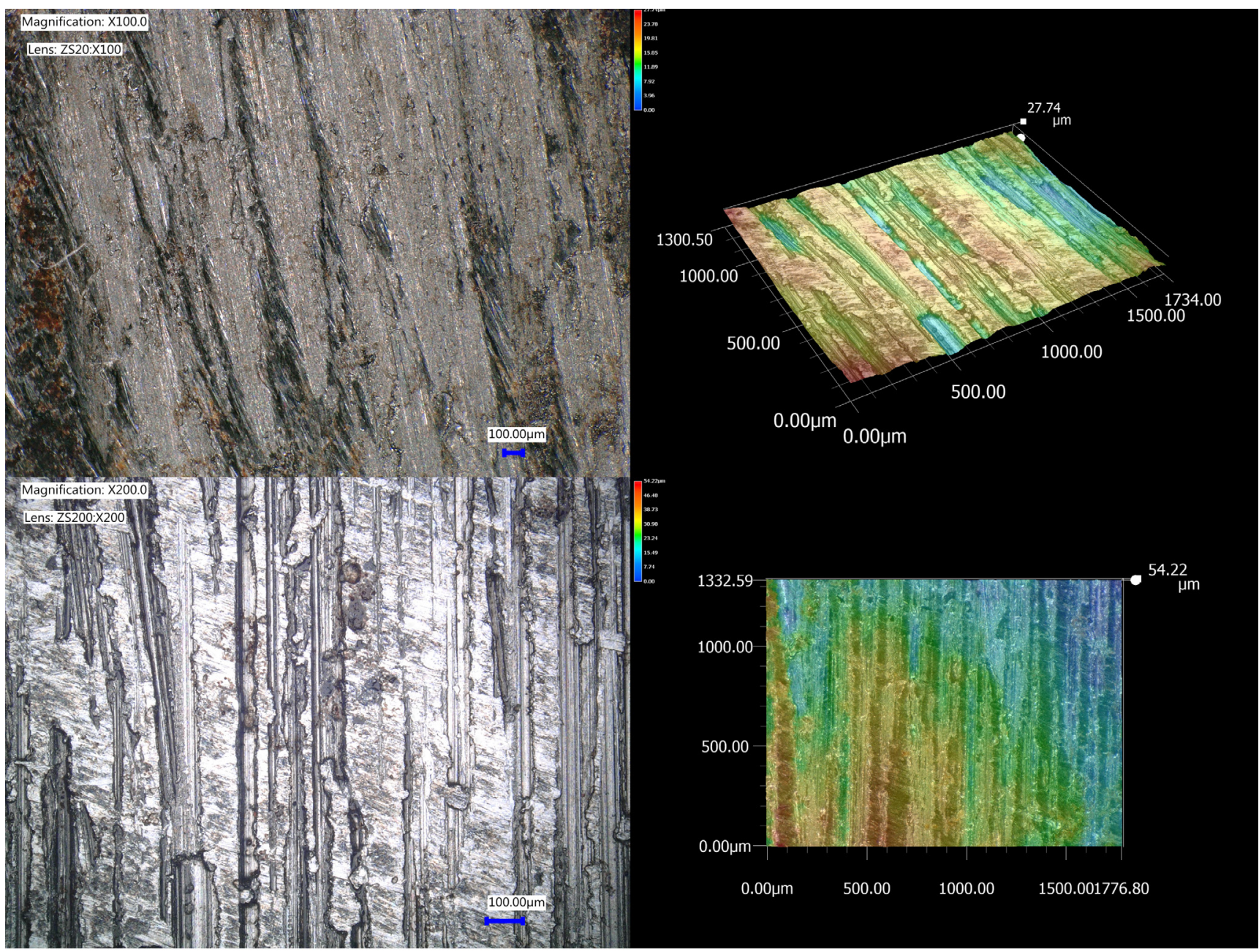

Fig. 9 Optical image on the surface of the steel plate (after test and lubricated using lubricant without silica-coated magnetite particles).

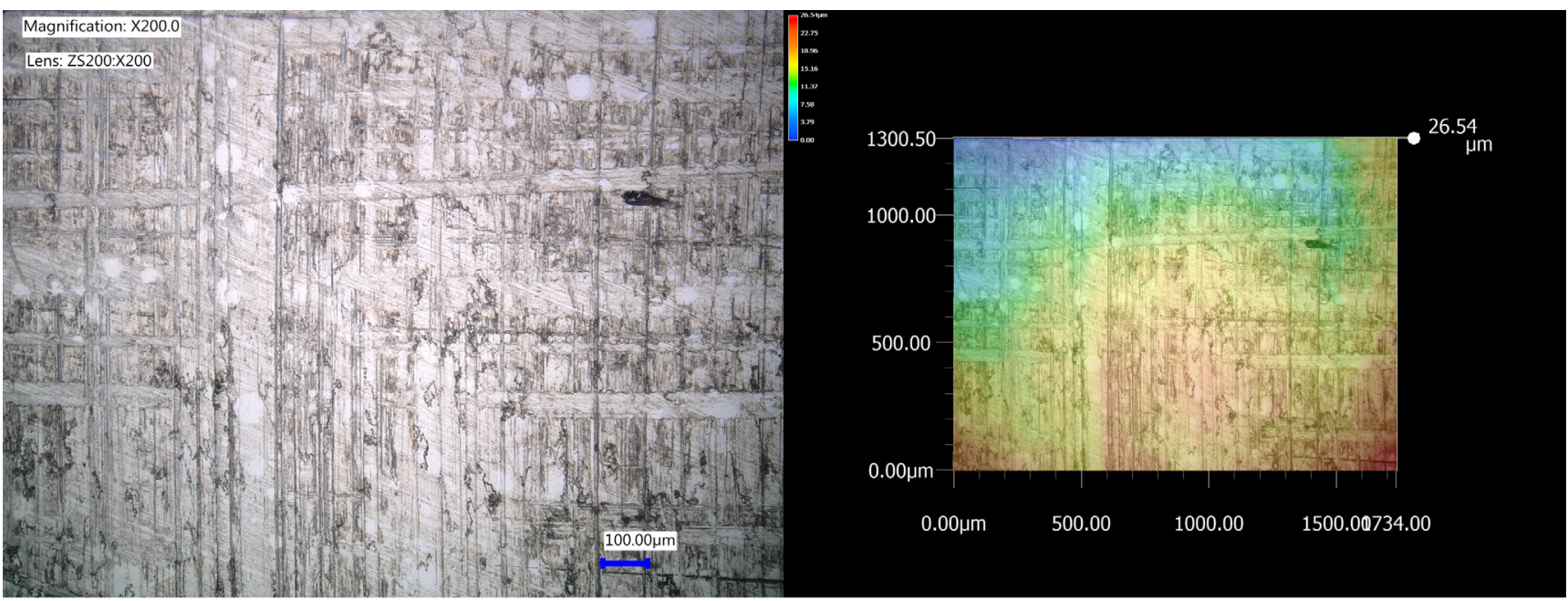

Fig. 10 Optical image on the surface of the steel plate (after test and lubricated using ferro-lubricant). 


\section{References}

[1] Shahnazar, S., Bagheri, S., Abd Hamid, S. B. "Enhancing lubricant properties by nanoparticle additives", International Journal of Hydrogen Energy, 41(4), pp. 3153-3170, 2016.

https://doi.org/10.1016/j.ijhydene.2015.12.040

[2] Budai, C., Kovács, L. L. "Friction Effects on Stability of a Digitally Controlled Pendulum", Periodica Polytechnica Mechanical Engineering, 59(4), pp. 176-181, 2015. https://doi.org/10.3311/PPme.8298

[3] Anvari, A. "Friction Coefficient Variation with Sliding Velocity in Copper with Copper Contact", Periodica Polytechnica Mechanical Engineering, 60(3), pp. 137-141, 2016. https://doi.org/10.3311/PPme.8429

[4] Mikó, S. É. "Frictional Contact Finite Element Analysis of Pneumatic Cylinders", Periodica Polytechnica Mechanical Engineering, 60(1), pp. 50-57, 2016. https://doi.org/10.3311/PPme.8530

[5] Huang, J., Li, Y., Jia, X., Song, H. "Preparation and tribological properties of core-shell $\mathrm{Fe}_{3} \mathrm{O}_{4} @ \mathrm{C}$ microspheres", Tribology International, 129, pp. 427-435, 2019.

https://doi.org/10.1016/j.triboint.2018.08.036

[6] Alves, S. M., Barros, B. S., Trajano, M. F., Ribeiro, K. S. B., Moura, E. "Tribological behavior of vegetable oil-based lubricants with nanoparticles of oxides in boundary lubrication conditions", Tribology International, 65, pp. 28-36, 2013. https://doi.org/10.1016/j.triboint.2013.03.027

[7] Giacone, E., Mancò, S. "Energy efficiency measurement in industrial processes", Energy, 38(1), pp. 331-345, 2012.

https://doi.org/10.1016/j.energy.2011.11.054

[8] Buketov, A., Brailo, M., Yakushchenko, S., Sapronov, O., Vynar, V., Bezbakh, O., Negrutsa, R. "Investigation of Tribological Properties of Two-Component Bidisperse Epoxy-Polyester Composite Materials for Its Use in the Friction Units of Means of Sea Transport", Periodica Polytechnica Mechanical Engineering, 63(3), pp. 171-182, 2019. https://doi.org/10.3311/PPme.13161

[9] Hsu, S. M., Zhang, J., Yin, Z. "The Nature and Origin of Tribochemistry", Tribology Letters, 13(2), pp. 131-139, 2002. https://doi.org/10.1023/A:1020112901674

[10] Taylor, R. I. "Tribology and energy efficiency: from molecules to lubricated contacts to complete machines", Faraday Discussions, 156, pp. 361-382, 2012. https://doi.org/10.1039/c2fd00122e

[11] Ivanov, M., Shenderova, O. "Nanodiamond-based nanolubricants for motor oils", Current Opinion in Solid State and Materials Science, 21(1), pp. 17-24, 2017. https://doi.org/10.1016/j.cossms.2016.07.003

[12] Rasheed, A. K., Khalid, M., Rashmi, W., Gupta, T. C. S. M., Chan, A. "Graphene based nanofluids and nanolubricants - Review of recent developments", Renewable and Sustainable Energy Reviews, 63, pp. 346-362, 2016. https://doi.org/10.1016/j.rser.2016.04.072

[13] Narita, K., Iwai, T., Takekawa, D. "Lubricant Additives for Improving the Performance of Metal V-Belt Type CVTs", Tribology Online, 7(3), pp. 152-158, 2012. https://doi.org/10.2474/trol.7.152
[14] Nakano, M., Miyake, K., Korenaga, A., Ando, Y. "Effect of Lubricant Additives on the Tribological Properties of Nanostripe Surfaces", Tribology Online, 9(2), pp. 37-44, 2014.

https://doi.org/10.2474/trol.9.37

[15] Koshy, C. P., Rajendrakumar, P. K., Thottackkad, M. V. "Analysis of Tribological and Thermo-Physical Properties of SurfactantModified Vegetable Oil-Based CuO Nano-Lubricants at Elevated Temperatures - An Experimental Study", Tribology Online, 10(5), pp. 344-353, 2015.

https://doi.org/10.2474/trol.10.344

[16] Dassenoy, F. "Nanoparticles as Additives for the Development of High Performance and Environmentally Friendly Engine Lubricants", Tribology Online, 14(5), pp. 237-253, 2019. https://doi.org/10.2474/trol.14.237

[17] Matsumoto, N., Maeda, M., Kajita, K., Omiya, Y., Kinoshita, H. "Wood-Powder-Template-Based Syntheses and Tribology of Copper Oxide Particles as Lubricating Oil Additives", Tribology Online, 15(2), pp. 68-77, 2020.

https://doi.org/10.2474/trol.15.68

[18] Qu, M., Yao, Y., He, J., Ma, X., Feng, J., Liu, S., Hou, L., Liu X. "Tribological study of polytetrafluoroethylene lubricant additives filled with $\mathrm{Cu}$ microparticles or $\mathrm{SiO}_{2}$ nanoparticles", Tribology International, 110, pp. 57-65, 2017.

https://doi.org/10.1016/j.triboint.2017.02.010

[19] Wu, H., Zhao, J., Cheng, X., Xia, W., He, A., Yun, J. H., Huang, S., Wang, L., Huang, S., Wang, L., Huang, H., Jiao, S., Jiang, Z. "Friction and wear characteristics of $\mathrm{TiO}_{2}$ nano-additive waterbased lubricant on ferritic stainless steel", Tribology International, 117, pp. 24-38, 2018.

https://doi.org/10.1016/j.triboint.2017.08.011

[20] Ren, B., Gao, L., Xie, B., Li, M., Zhang, S., Zu, G., Ran, X. "Tribological properties and anti-wear mechanism of $\mathrm{ZnO} @$ graphene core-shell nanoparticles as lubricant additives", Tribology International, 144, Article Number: 106114, 2020. https://doi.org/10.1016/j.triboint.2019.106114

[21] Wang, L., Gong, P., Li, W., Luo, T., Cao, B. "Mono-dispersed Ag/ Graphene nanocomposite as lubricant additive to reduce friction and wear", Tribology International, 146, Article Number: 106228, 2020. https://doi.org/10.1016/j.triboint.2020.106228

[22] Zhu, H., Yang, D., Zhu, L. "Hydrothermal growth and characterization of magnetite $\left(\mathrm{Fe}_{3} \mathrm{O}_{4}\right)$ thin films", Surface and Coatings Technology, 201(12), pp. 5870-5874, 2007. https://doi.org/10.1016/j.surfcoat.2006.10.037

[23] Khashan, S., Dagher, S., Tit, N., Alazzam, A., Obaidat, I. "Novel method for synthesis of $\mathrm{Fe}_{3} \mathrm{O}_{4} @ \mathrm{TiO}_{2}$ core/shell nanoparticles", Surface and Coatings Technology, 322, pp. 92-98, 2017. https://doi.org/10.1016/j.surfcoat.2017.05.045

[24] Zhou, G., Zhu, Y., Wang, X., Xia, M., Zhang, Y., Ding, H. "Sliding tribological properties of $0.45 \%$ carbon steel lubricated with $\mathrm{Fe}_{3} \mathrm{O}_{4}$ magnetic nano-particle additives in baseoil", Wear, 301(1-2), pp. 753-757, 2013. https://doi.org/10.1016/j.wear.2013.01.027

[25] Xiang, L., Gao, C., Wang, Y., Pan, Z., Hu, D. "Tribological and tribochemical properties of magnetite nanoflakes as additives in oil lubricants", Particuology, 17, pp. 136-144, 2014. https://doi.org/10.1016/j.partic.2013.09.004 
[26] Xu, Y., Geng, J., Peng, Y., Liu, Z., Yu, J., Hu, X. "Lubricating mechanism of $\mathrm{Fe}_{3} \mathrm{O}_{4} @ \mathrm{MoS}_{2}$ core-shell nanocomposites as oil additives for steel/steel contact", Tribology International, 121, pp. 241-251, 2018. https://doi.org/10.1016/j.triboint.2018.01.051

[27] Hong, R. Y., Li, J. H., Zhang, S. Z., Li, H. Z., Zheng, Y., Ding, J. M., Wei, D. G. "Preparation and characterization of silica-coated $\mathrm{Fe}_{3} \mathrm{O}_{4}$ nanoparticles used as precursor of ferrofluids", Applied Surface Science, 255(6), pp. 3485-3492, 2009. https://doi.org/10.1016/j.apsusc.2008.09.071

[28] Cendrowski, K., Sikora, P., Zielinska, B., Horszczaruk, E., Mijowska, E. "Chemical and thermal stability of core-shelled magnetite nanoparticles and solid silica", Applied Surface Science, 407, pp. 391-397, 2017. https://doi.org/10.1016/j.apsusc.2017.02.118

[29] Fan, Y., Li, C., Chen, Z., Ma, F., Chen, H. "Study on fabrication of superhydrophobic and superparamagnetic functional coatings and its properties", Surface and Coatings Technology, 213, pp. 8-14, 2012.

https://doi.org/10.1016/j.surfcoat.2012.09.056

[30] Bitar, A., Vega-Chacón, J., Lgourna, Z., Fessi, H., Jafelicci, M., Elaissari, A. "Submicron silica shell-magnetic core preparation and characterization", Colloids and Surfaces A: Physicochemical and Engineering Aspects, 537, pp. 318-324, 2018. https://doi.org/10.1016/j.colsurfa.2017.10.034

[31] Alamri, H., Al-Shahrani, A., Bovero, E., Khaldi, T., Alabedi, G., Obaid, W., Al-Taie, I., Fihri, A. "Self-cleaning superhydrophobic epoxy coating based on fibrous silica-coated iron oxide magnetic nanoparticles", Journal of Colloid Interface Science, 513, pp. 349-356, 2018.

https://doi.org/10.1016/j.jcis.2017.11.042

[32] de Mendonça, E. S. D. T., Brittode de Faria, A. C., Dias, S. C. L., Aragón, F. F. H., Mantilla, J. C., Coaquira, J. A. H., Dias, J. A. "Effects of silica coating on the magnetic properties of magnetite nanoparticles", Surfaces and Interfaces, 14, pp. 34-43, 2019. https://doi.org/10.1016/j.surfin.2018.11.005

[33] Yao, Y., Miao, S., Yu, S., Ma, L. P., Sun, H., Wang, S. "Fabrication of $\mathrm{Fe}_{3} \mathrm{O}_{4} / \mathrm{SiO}_{2}$ core/shell nanoparticles attached to graphene oxide and its use as an adsorbent", Journal of Colloid and Interface Science, 379(1), pp. 20-26, 2012. https://doi.org/10.1016/j.jcis.2012.04.030

[34] Lesiak, B., Rangam, N., Jiricek, P., Gordeev, I., Tóth, J., Kövér, L., Mohai, M., Borowicz, P. "Surface Study of $\mathrm{Fe}_{3} \mathrm{O}_{4}$ Nanoparticles Functionalized With Biocompatible Adsorbed Molecules", Frontiers in Chemistry, 7, Article Number: 642, 2019. https://doi.org/10.3389/fchem.2019.00642

[35] Araújo-Neto, R. P., Silva-Freitas, E. L., Carvalho, J. F., Pontes, T. R. F., Silva, K. L., Damasceno, I. H. M., Egito, E. S. T., Dantas, A. L., Morales, M. A., Carriço, A. S. "Monodisperse sodium oleate coated magnetite high susceptibility nanoparticles for hyperthermia applications", Journal of Magnetism and Magnetic Materials, 364, pp. 72-79, 2014.

https://doi.org/10.1016/j.jmmm.2014.04.001
[36] Dayana, I., Sembiring, T., Tetuko, A. P., Sembiring, K., Maulida, N., Cahyarani, Z., Setiadi, E. A., Asri, N. S., Ginting, M., Sebayang, P. "The effect of tetraethyl orthosilicate (TEOS) additions as silica precursors on the magnetite nano-particles $\left(\mathrm{Fe}_{3} \mathrm{O}_{4}\right)$ properties for the application of ferro-lubricant", Journal of Molecular Liquids, 294, Article Number: 111557, 2019.

https://doi.org/10.1016/j.molliq.2019.111557

[37] Syam Sundar, L., Singh, M. K., Sousa, A. C. M. "Investigation of thermal conductivity and viscosity of $\mathrm{Fe}_{3} \mathrm{O}_{4}$ nanofluid for heat transfer applications", International Communication of Heat Mass Transfer, 44, pp. 7-14, 2013.

https://doi.org/10.1016/j.icheatmasstransfer.2013.02.014

[38] Mahbubul, I. M., Saidur, R., Amalina, M. A. "Latest developments on the viscosity of nanofluids", International Journal of Heat Mass Transfer, 55(4), pp. 874-885, 2012.

https://doi.org/10.1016/j.ijheatmasstransfer.2011.10.021

[39] Wang, L., Wang, Y., Yan, X., Wang, X., Feng, B. "Investigation on viscosity of $\mathrm{Fe}_{3} \mathrm{O}_{4}$ nanofluid under magnetic field", International Communication of Heat Mass Transfer, 72, pp. 23-28, 2016. https://doi.org/10.1016/j.icheatmasstransfer.2016.01.013

[40] Ahmadi Nadooshan, A., Eshgarf, H., Afrand, M. "Measuring the viscosity of $\mathrm{Fe}_{3} \mathrm{O}_{4}$-MWCNTs/EG hybrid nanofluid for evaluation of thermal efficiency: Newtonian and non-Newtonian behavior", Journal of Molecular Liquids, 253, pp. 169-177, 2018. https://doi.org/10.1016/j.molliq.2018.01.012

[41] Asadi, A., Asadi, M., Rezaei, M., Siahmargoi, M., Asadi, F. "The effect of temperature and solid concentration on dynamic viscosity of MWCNT/MgO (20-80)-SAE50 hybrid nano-lubricant and proposing a new correlation: An experimental study", International Communication of Heat Mass Transfer, 78, pp. 48-53, 2016. https://doi.org/10.1016/j.icheatmasstransfer.2016.08.021

[42] Chen, H. J., Wang, Y. M., Qu, J. M., Hong, R. Y., Li, H. Z. "Preparation and characterization of silicon oil based ferrofluid", Applied Surface Science, 257(24), pp. 10802-10807, 2011. https://doi.org/10.1016/j.apsusc.2011.07.103

[43] Alsaady, M., Fu, R., Li, B., Boukhanouf, R., Yan, Y. "Thermophysical properties and thermo-magnetic convection of ferrofluid", Applied Thermal Engineering, 88, pp. 14-21, 2015. https://doi.org/10.1016/j.applthermaleng.2014.09.087

[44] Wang, J. J., Zheng, R. T., Gao, J. W., Chen, G. "Heat conduction mechanisms in nanofluids and suspensions", Nano Today, 7(2), pp. 124-136, 2012.

https://doi.org/10.1016/j.nantod.2012.02.007

[45] Dinesh, R., Giri Prasad, M. J., Rishi Kumar, R., Jerome Santharaj, N., Santhip, J., Abhishek Raaj, A. S. "Investigation of Tribological and Thermophysical Properties of Engine Oil Containing Nano additives", Materials Today, 3(1), pp. 45-53, 2016. https://doi.org/10.1016/j.matpr.2016.01.120

[46] Yang, L., Mao, M., Huang, J. N., Ji, W. "Enhancing the thermal conductivity of SAE 50 engine oil by adding zinc oxide nano-powder: An experimental study", Powder Technology, 356, pp. 335-341, 2019.

https://doi.org/10.1016/j.powtec.2019.08.031 
[47] Lin, L., Kedzierski, M. A. "Specific heat of aluminum-oxide nanolubricants", International Journal of Heat Mass Transfer, 126(B), pp. 1168-1176, 2018.

https://doi.org/10.1016/j.ijheatmasstransfer.2018.06.077

[48] Wrenick, S., Sutor, P., Pangilinan, H., Schwarz, E. E. "Heat Transfer Properties of Engine Oils", Proceeding of World Tribology Congress III, Washington, DC, USA, 2005, pp. 595-596. https://doi.org/10.1115/WTC2005-64316

[49] Wu, N., Hu, N., Zhou, G., Wu, J. "Tribological properties of lubricating oil with micro/nano-scale $\mathrm{WS}_{2}$ particles", Journal of Experimental Nanoscience, 13(1), pp. 27-38, 2018. https://doi.org/10.1080/17458080.2017.1405164

[50] Moore, D. F., Booker, J. F. "Principles and Applications of Tribology", Journal of Lubrication Technology, 98(4), Article Number: 635, 1976 https://doi.org/10.1115/1.3452952

[51] Popov, V. L. "Contact Mechanics and Friction: Physical Principles and Applications", Springer, Berlin, Heidelberg, Germany, 2010. https://doi.org/10.1007/978-3-642-10803-7
[52] Ali, M. K. A., Xianjun, H., Mai, L., Bicheng, C., Turkson, R. F., Qingping, C. "Reducing frictional power losses and improving the scuffing resistance in automotive engines using hybrid nanomaterials as nano-lubricant additives", Wear, 364-365, pp. 270-281, 2016. https://doi.org/10.1016/j.wear.2016.08.005

[53] Dai, W., Kheireddin, B., Gao, H., Liang, H. "Roles of nanoparticles in oil lubrication", Tribology International, 102, pp. 88-98, 2016. https://doi.org/10.1016/j.triboint.2016.05.020

[54] Nicoletti, R. "The Importance of the Heat Capacity of Lubricants With Nanoparticles in the Static Behavior of Journal Bearings", Journal of Tribology, 136(4), Article Number: 044502, 2014. https://doi.org/10.1115/1.4027861

[55] Shen, C., Huang, W., Ma, G., Wang, X. "A novel surface texture for magnetic fluid lubrication", Surface and Coatings Technology, 204(4), pp. 433-439, 2009. https://doi.org/10.1016/j.surfcoat.2009.08.003

[56] Ali, M. K. A., Xianjun, H., Mai, L., Qingping, C., Turkson, R. F., Bicheng, C. "Improving the tribological characteristics of piston ring assembly in automotive engines using $\mathrm{Al}_{2} \mathrm{O}_{3}$ and $\mathrm{TiO}_{2}$ nanomaterials as nano-lubricant additives", Tribology International, 103, pp. 540-554, 2016.

https://doi.org/10.1016/j.triboint.2016.08.011 